\title{
The environmental and economic effects of innovative measures in urban parcels delivery
}

\author{
M. E. Lopez Lambas ${ }^{1} \&$ S. Ricci ${ }^{2}$ \\ ${ }^{1}$ Universidad Politecnica de Madrid, Spain \\ ${ }^{2}$ Sapienza Università di Roma - DICEA - Area Trasporti, Italy
}

\begin{abstract}
The main scope of this research is to identify and evaluate solutions to redesign the parcels delivery logistic process to achieve higher level of quality, lower operational costs, energy consumptions and air pollution. The study is starting from the analysis of the delivery process managed by a leader company operating in Rome. Main delivery flows, personnel and fleet management costs, quality performances and environmental impacts are investigated. The results of this analysis are benchmarked with other European situations. On the basis of the feedback of this analysis, a set of operational measures, potentially able tackle the objectives, are identified and assessed by means of a simulative approach. The assessment is based on environmental and economic indicators allowing the comparison between new and reference scenarios from the viewpoints of the key players: operator, customer and Society. Moreover, the operational measures are combined into alternative packages by looking for the sets capable to maximize the benefits for the key players. The methodology, tested on Rome case study, is general and flexible enough to be extended to parcels delivery problem in different urban contexts, as well as to similar urban distribution problems (e.g. press, food, security, school).
\end{abstract}

Keywords: urban transport, freight distribution, parcels delivery.

\section{Introduction}

The parcels delivery in urban areas is a relevantly impacting activity, both on the road traffic and the environment itself. As the same time the quality of the service provided to the final customer is often limited low rate of efficiency and 
productivity. Moreover, the EC Directives about road vehicles emissions are strongly pushing towards a renewal of the fleets. In this context the liberalization of postal and parcel market stimulates the multiplication of companies aiming at increase their competitiveness. Therefore, the need to assess the measures capable to fulfill environmental and economic aims of operators, customers and Society is a key aspect to be approached by studies and researches on methods and applications.

\section{Typical organization of parcels delivery services}

The organization of parcels delivery services is often differentiated according to the dimension of operating companies, the covered area, the fleet typology, etc. Nevertheless, some common coordinates of various structures may be identified, particularly with reference to urban distribution, which is normally based on logistic centres fed by long distance transport systems and feeding last mile distribution to final destinations. These centres normally operate at least the following functions: 1) reception from long distance feeders; 2) assignment to final destination area; 3) delivery to the final address by destination area. Moreover, for key customers handling large quantity of parcels, additional dedicated services and discounted fares may be provided. The equipment of these centres normally includes conveyor belts switching the parcels towards buffer areas feeding distribution vehicles. All the process is normally managed by tracking systems based on identification codes. The domiciliary distribution is normally the critical segment of the process due to various reasons: high rate of undelivered parcels, delays due to internal causes (e.g. failures in equipment or process) and external causes (e.g. road traffic or absence of acceptors).

\section{Case study: parcels delivery in Rome}

\subsection{Organization and traffic}

The selected case study is the Rome metropolitan area, which is characterized by organizational complexity and relevant impact on road traffic, due to the quantity of handled parcels and the dimension of the area itself. The parcels delivery main center in Rome manages a global yearly volume of around 5 millions of units (daily average value of about 17,400 units). About $49 \%$ of this traffic is destined to the city of Rome, the remaining $51 \%$ is destined to the surrounding regions served by the same centers (Lazio and Umbria). The following analysis are developed with reference to the urban distribution only (about 8,900 units/day). The recorded flows show some relevant seasonal fluctuation in comparison with the average value: maximum in March (+34\%) and minimum in August (-58\%). The concerned area is divided into 134 zones: 71 zones are directly served by the main center, the remaining zones are served by 4 sub-centers. The amount of traffic directly served by the main center includes about 4,800 units. 


\subsection{Delivery personnel and tasks durations}

The operators in charge of the delivery are 93 (71 simultaneous working) with organized in single operator teams, except for central area where the parking difficulties require double operators teams. The average personnel cost is around 27,000 euro/operator/year, corresponding to around 2.5 million euro/year for the whole service. Every working day the delivery teams perform a delivery tour divided into the phases identified in Table 1.

Table 1: Average duration of delivery tour phases.

\begin{tabular}{|l|c|}
\hline \multicolumn{1}{|c|}{ Delivery tour phases } & Average duration [min] \\
\hline Tour preparation & 60 \\
\hline Parcels loading & 30 \\
\hline Trip to delivering zone & 40 \\
\hline Parcels Delivery & 185 \\
\hline Undelivered parcels unloading & 20 \\
\hline Trip back to the main center & 40 \\
\hline Accounting & 55 \\
\hline TOTAL & $\mathbf{4 3 0}$ \\
\hline
\end{tabular}

In the same table the average duration of these phases have been quantified on the basis of an extended field investigation based on the reports compiled by the operators themselves. The total tour length, depending upon the distances between the main center and the single zones is variable between 20 and $64 \mathrm{~km}$. The mean delivery time for a single parcel is variable between 1.41 and $3.54 \mathrm{~min}$. The average amount of undelivered parcels is $28 \%(16 \%$ due to the absence of the acceptor and $12 \%$ due to the lack of time in the planned tour). The average stocking time in the center, before the delivery, is variable from 1 to 8 days.

\subsection{Delivery fleet}

The delivery fleet is composed of 103 vans of various diesel and turbo-diesel motorized models by Alfa Romeo, Fiat, Iveco and Volkswagen. The performances of these vehicles are synthetically reported in Table 2.

Table 2: Performances of delivery vehicles.

\begin{tabular}{|l|c|}
\hline \multicolumn{1}{|c|}{ Performance } & Value \\
\hline Displacement $\left[\mathrm{m}^{3}\right]$ & $2800 \div 4570$ \\
\hline Max power $[\mathrm{kW}]$ & $52 \div 90$ \\
\hline Loading volume $\left[\mathrm{m}^{3}\right]$ & $9 \div 14$ \\
\hline Tare $[\mathrm{kg}]$ & $1795 \div 3540$ \\
\hline Payload $[\mathrm{kg}]$ & $875 \div 2460$ \\
\hline Total mass $[\mathrm{kg}]$ & $2670 \div 6000$ \\
\hline Range consumption $[\mathrm{km} / 1]$ & $7.4 \div 11.6$ \\
\hline
\end{tabular}


The fleet is almost old, with an average age of about 14 years and a peak of 20 years. Their operational costs have been estimated on the basis of the analysis accounting report [2]. The results are reported in table 3 .

Table 3: Average operational costs of delivery fleet.

\begin{tabular}{|l|c|}
\hline \multicolumn{1}{|c|}{ Average costs } & Value \\
\hline $\begin{array}{l}\text { Variable costs (fuel, lubricant, tires, maintenance and repair, } \\
\text { depreciation charge) [euro/km] }\end{array}$ & $0.18 \div 0.24$ \\
\hline Fixed costs (depreciation interest, taxes and insurance) [euro/year] & $1273 \div 3061$ \\
\hline
\end{tabular}

The environmental performances of this fleet have been estimated by a weighted estimation based on the crossing between the progressive EURO emissions limits and the vans' age (table 4).

Table 4: Estimated average emissions for the whole fleet.

\begin{tabular}{|l|c|}
\hline Matter & Emissions $[\mathrm{g} / \mathrm{kWh}]$ \\
\hline $\mathrm{NO}_{\mathrm{x}}$ & 15.02 \\
\hline $\mathrm{THC}$ & 2.84 \\
\hline $\mathrm{CO}$ & 11.34 \\
\hline $\mathrm{PM}$ & 0.62 \\
\hline
\end{tabular}

On the basis of the calorific value of diesel fuel $(13.25 \mathrm{kWh} / \mathrm{l})$, the emissions have been related to its consumptions, moreover the $\mathrm{CO}_{2}$ emissions have been calculated on the basis of the emission rate $3.01 \mathrm{~kg} / 1$ [1].

\subsection{Total cost of delivery}

On the basis of the acquired elements, it has been quantified the total cost of delivery: about 2.9 million euro/year. It takes into account: personnel costs (about 2.5 million euro/year), vehicles operational costs (about 0.3 million euro/year) and additional costs for buildings management (energy need, maintenance, etc.) (about 0.1 million/year). The corresponding unit cost is 2.23 euro/parcel.

\section{European benchmarking}

The preliminary analysis on the state-of-the-art of delivery are completed by an international benchmarking among the corresponding services in Rome, Milan, Turin and London. The benchmarking is based both on structural data and performance indicators, which are synthetically summarized in tables 5 and 6 . In London a larger traffic is served with a relevantly higher productivity and lower unit cost, mainly due to the smaller fleet in comparison with Rome, the larger daily time dedicated to the delivery and the lower rate of undelivered parcels in comparison with all the other cities. The performances in Italian cities are almost similar, with the single exception of the particularly high rate of undelivered parcels in Milan. 
Table 5: Structural parameters benchmarking of parcels delivery services.

\begin{tabular}{|l|c|c|c|c|}
\hline \multicolumn{1}{|c|}{ Parameter } & London & Milan & Rome & Turin \\
\hline Yearly traffic [delivered parcels] & $2,292,000$ & $1,704,000$ & $1,301,000$ & 744,000 \\
\hline Daily parcels delivery time [min] & 410 & 135 & 185 & 165 \\
\hline Fleet dimension [vehicles] & 53 & 52 & 103 & 48 \\
\hline Personnel [delivery operators] & 53 & 120 & 93 & 52 \\
\hline Daily unit load [parcels/vehicle] & 150 & 114 & 44 & 54 \\
\hline
\end{tabular}

Table 6: Performance indicators benchmarking of parcels delivery services.

\begin{tabular}{|l|c|c|c|c|}
\hline \multicolumn{1}{|c|}{ Parameter } & London & Milan & Rome & Turin \\
\hline Daily personnel productivity [parcels/operator] & 126 & 50 & 51 & 50 \\
\hline Undelivered parcels [\%] & 7 & 46 & 28 & 29 \\
\hline Unit delivery cost [euro/parcel] & 0.90 & 2.25 & 2.23 & 2.22 \\
\hline
\end{tabular}

\section{Technological and operational measures}

\subsection{Aims from different viewpoints}

In order to increase the performances of the delivery services, various potentially effective technological and operational measures have been identified and tested. The increase of the performances is evaluated from the different viewpoints of key subjects interacting around the services:

- the delivery company, willing to decrease the total cost of the service and to increase the customer satisfaction to attract larger traffic;

- the final customer, willing to increase the quality of service;

- the Society, willing to decrease the environmental impact of the delivery vehicles.

The identified measures [3,4] are described and assessed in the following paragraphs.

\subsection{Use of electric vehicles}

An extended investigation on commercially available electric vehicles allowed to highlight the performances summarized in table 7 .

Table 7: Performances of electric vans.

\begin{tabular}{|l|c|}
\hline \multicolumn{1}{|c|}{ Performance } & Value \\
\hline Loading volume $\left[\mathrm{m}^{3}\right]$ & $0.7 \div 9.0$ \\
\hline Payload $[\mathrm{kg}]$ & $300 \div 1300$ \\
\hline Operational range $[\mathrm{km}]$ & $40 \div 100$ \\
\hline Recharging time $[\mathrm{h}]$ & $6 \div 12$ \\
\hline Maximum speed $[\mathrm{km} / \mathrm{h}]$ & $29 \div 70$ \\
\hline
\end{tabular}


This performance have been cross checked with average dimensions of parcels $\left(43\right.$ units $\left./ \mathrm{m}^{3}\right)$, their average weight $(2.5 \mathrm{~kg})$, the average load and the total distance run for each tour: only 11/71 zones (15\%) cannot be served by the electric vehicles, due to lack either in loading volume or in operational range. The operational costs of the electric vehicles have been calculated on the basis of data provided by the producers and resulting from pilot applications in similar services (table 8).

Table 8: Average operational costs of electric vans.

\begin{tabular}{|l|c|}
\hline \multicolumn{1}{|c|}{ Average costs } & Value \\
\hline $\begin{array}{l}\text { Variable costs (fuel, lubricant, tires, maintenance and repair, } \\
\text { depreciation charge) [euro/km] }\end{array}$ & 0.46 \\
\hline Fixed costs (depreciation interest, taxes and insurance) [euro/year] & 2812 \\
\hline
\end{tabular}

The innovative scenario includes the use of electric vehicles for the delivery in 60 zones and a residual diesel based service for the remaining 11 zones [5]. In this scenario the total operational cost is reduced of $4.4 \%$ (about 77,500 euro). The emissions are recalculated taking anyway into account the contribution of the electric power plants, which in Italy is largely produced from non-renewable sources (table 9).

Table 9: Estimated average emissions of electric power plant in Italy.

\begin{tabular}{|l|c|}
\hline Matter & Emissions $[\mathrm{g} / \mathrm{kWh}]$ \\
\hline $\mathrm{CO}_{2}$ & 797.00 \\
\hline $\mathrm{NO}_{\mathrm{x}}$ & 1.70 \\
\hline $\mathrm{THC}$ & 1.01 \\
\hline $\mathrm{CO}$ & 0.28 \\
\hline $\mathrm{PM}$ & 0.16 \\
\hline
\end{tabular}

The comparison with the present situation shows a reduction of energy consumption of $2238 \mathrm{kWh} /$ year (about $67 \%$ of the present amount), a reduction of $\mathrm{CO}_{2}$ emissions of $216 \mathrm{~kg} /$ year (about $28 \%$ of the present amount) and an average reduction of the other local emissions around $91 \%$.

\subsection{Implementation of a back-office}

The proposed measure is the implementation of a back-office in charge to optimize the preparation of the delivery tours and to manage the accounting activities in substitution of the delivery operators. The measure may be completed by 2 different scenarios, characterized by the potential uses of the saved time: 1) to increase the time dedicated to the delivery itself by increasing the daily parcels deliveries, the corresponding income and the customer satisfaction due to the reduced time to delivery; 2) to decrease the working time of the operators by saving costs without modifying the delivery performances. The different effects on the use of time are summarized in table 10. 
Scenario 1 allows a $46 \%$ increase of delivery time and delivered parcels. The increase of distances run by the vehicles is about $7 \mathrm{~km} \mathrm{(20 \% )}$ with corresponding increase in energy consumptions and emissions. Nevertheless, due to the increased traffic, unit consumptions and emissions related to a single parcel are reduced of approximately $17 \%$. The back-office implementation requires a personnel increase of 10 units. For the total cost the increase is $10 \%$. On these basis the unit delivery cost decreases from 2.23 to 1.68 euro/parcel $(-25 \%)$. Moreover, the quality of the service is increased due to the decrease of the average waiting time to delivery from 4.0 to 2.7 days $(-32 \%)$.

Table 10: Comparison of average duration of delivery tour phases with back-office (differences highlighted in grey).

\begin{tabular}{|l|c|c|c|}
\hline \multirow{2}{*}{ Delivery tour phases } & \multicolumn{3}{c|}{ Average duration [min] } \\
\cline { 2 - 4 } & Present situation & Scenario 1 & Scenario 2 \\
\hline Tour preparation & 60 & - & - \\
\hline Parcels loading & 30 & 45 & 30 \\
\hline Trip to delivering zone & 40 & 40 & 40 \\
\hline Parcels Delivery & 185 & 270 & 185 \\
\hline Undelivered parcels unloading & 20 & 20 & 20 \\
\hline Trip back to the main center & 40 & 40 & 40 \\
\hline Accounting & 55 & 15 & 15 \\
\hline TOTAL & $\mathbf{4 3 0}$ & $\mathbf{4 3 0}$ & $\mathbf{3 3 0}$ \\
\hline
\end{tabular}

In Scenario 2 delivery time, delivered parcels, energy consumptions and emissions are unchanged, the variation are in personnel cost only reduced of $12 \%$ : an increase of 10 back-office operators against a decrease of 21 delivery operators. On these basis the unit delivery cost decreases from 2.23 to 2.00 euro/parcel $(-10 \%)$. Moreover, a limited decrease of the waiting time from 4.0 to 3.9 days is experienced.

\subsection{Implementation of a call center}

The proposed measure is the implementation of a call center to assist the management of the undelivered parcels. These parcels will be unloaded to the call center, which will receive the phone calls of customers, who were not found during the first tour, and redress the parcel towards either the delivery during a second tour or the direct pick-up by the acceptor. During an experimental phase the percentage of phone contacts resulted almost low $(16 \%)$, nevertheless a potential rate of $50 \%$ is considered reachable thanks to a robust information campaign. The saved time can be used according to the same scenarios introduced for the back-office measure, with the effects summarized in table 11.

Scenario 1 allows a limited (9\%) increase of delivery time and delivered parcels. The increase of distances run by the vehicles is about $1.5 \mathrm{~km}$ with corresponding limited increase in energy consumptions and emissions well balanced ( $-4 \%$ globally) by the increase of delivered parcels. The call center implementation requires a personnel increase of 2 units only. For the total cost 
the increase is $2 \%$. On these basis the unit delivery cost decreases from 2.23 to 2.08 euro/parcel (-7\%). Moreover, a limited decrease of the waiting time from 4.0 to 3.5 days is experienced.

In Scenario 2 delivery time, delivered parcels, energy consumptions and emissions are unchanged, the variation are in personnel cost only, reduced of $2 \%$ : an increase of 2 call center operators against a decrease of 4 delivery operators. On these basis the unit delivery cost decreases from 2.23 to 2.18 euro/parcel (-2\%).

Table 11: Comparison of average duration of delivery tour phases with call center (differences highlighted in grey).

\begin{tabular}{|l|c|c|c|}
\hline \multirow{2}{*}{ Delivery tour phases } & \multicolumn{3}{|c|}{ Average duration [min] } \\
\cline { 2 - 4 } & Present situation & Scenario 1 & Scenario 2 \\
\hline Tour preparation & 60 & 60 & 60 \\
\hline Parcels loading & 30 & 35 & 30 \\
\hline Trip to delivering zone & 40 & 40 & 40 \\
\hline Parcels Delivery & 185 & 200 & 185 \\
\hline Undelivered parcels unloading & 20 & - & - \\
\hline Trip back to the main center & 40 & 40 & 40 \\
\hline Accounting & 55 & 55 & 55 \\
\hline TOTAL & $\mathbf{4 3 0}$ & $\mathbf{4 3 0}$ & $\mathbf{4 1 0}$ \\
\hline
\end{tabular}

\subsection{Delocalization of distribution centers}

The proposed measure is the delocalization of distribution centers from 1 to 3 different sites in order to reduce the length of the trip to delivery zones. The present distribution of volumes towards destination zones allow to calculate the optimal location of the centers capable to minimize the runs: the new centers require an average trip to the delivery zones respectively reduced to 12,18 and $20 \mathrm{~min}$ (present duration: $40 \mathrm{~min}$ ). Nevertheless, additional direct trips from the main center to the new delocalized centers are required (38 and $45 \mathrm{~min}$ ) as well as the corresponding loading and unloading phases (161 and $167 \mathrm{~min}$ ) for a total daily duration of $410 \mathrm{~min}$. Moreover new buildings (approximately $1600 \mathrm{~m}^{2}$ ) are required, whose renting cost has been estimated by a market enquiry in about 5.4 euro $/ \mathrm{m}^{2}$. Once more the saved time can be used according to the same scenarios introduced for the back-office and call center measures, with the effects summarized in table 12.

Scenario 1 allows a 21\% increase of delivery time and delivered parcels. The distances decrease (about $-50 \%$ ) due to the delocalization, but simultaneously increase of about $35 \mathrm{~km} / \mathrm{vehicle}$ due to the additional trips between main and decentralized centers, with a balance of $-19 \%$, which increases to $-34 \%$ by delivered unit, due to the simultaneous increase of traffic, with corresponding decrease of energy consumptions and emissions. The decentralization requires an addition of 18 operators for offices and transfer between centers. For the total cost the increase is $19 \%$. On these basis the economic result is negative: the unit 
delivery cost increases from 2.23 to 2.27 euro/parcel $(+2 \%)$. Moreover, the quality of the service is increased due to the decrease of the average waiting time to delivery from 4 to 3 days.

In Scenario 2 delivery time the energy consumptions and emissions decrease due to the decentralization with a balance, discounted of the increase for transfers between centers, of $-26 \%$, the variation in personnel cost are $9 \%$ : an increase of 18 new operators against a decrease of 8 delivery operators. On these basis the unit delivery cost further increases from 2.23 to 2.53 euro/parcel $(+13 \%)$.

Table 12: Comparison of average duration of delivery tour phases with decentralization (differences highlighted in grey).

\begin{tabular}{|l|c|c|c|}
\hline \multirow{2}{*}{ Delivery tour phases } & \multicolumn{3}{c|}{ Average duration [min] } \\
\cline { 2 - 4 } & Present situation & Scenario 1 & Scenario 2 \\
\hline Tour preparation & 60 & 60 & 60 \\
\hline Parcels loading & 30 & 35 & 30 \\
\hline Trip to delivering zone & 40 & 20 & 20 \\
\hline Parcels Delivery & 185 & 225 & 185 \\
\hline Undelivered parcels unloading & 20 & 20 & 20 \\
\hline Trip back to the main center & 40 & 15 & 15 \\
\hline Accounting & 55 & 55 & 55 \\
\hline TOTAL & $\mathbf{4 3 0}$ & $\mathbf{4 3 0}$ & $\mathbf{3 8 5}$ \\
\hline
\end{tabular}

\section{Identification of optimal measures}

The results achievable by means of technological and operational measures described in $\S 5$ have been matched with the viewpoints of the concerned main stakeholders: the results of this matching are summarised in Table 13.

From the viewpoint of the operator the implementation of the back-office (scenario B1) is the most fruitful for costs saving and can be introduced in combination with the use of electric vehicles (scenario EV) and the implementation of a call center (scenario $\mathrm{C} 1$ ).

From the viewpoint of the customer the implementation of a call center (scenario $\mathrm{C} 1$ ) is the most effective and can be positively combined with backoffice (scenario B1) and center delocalization (scenario D1).

From the viewpoint of the Society the most effective measure is largely the introduction of the electric vehicles (scenario EV), theoretically combinable with any other measure, but of course with a limitation of the advantages brought by scenarios B1, C1 and D1, due to the constraints in operational range and payload allowing to satisfy only partially the potential additional traffic volumes.

Indeed, for any combination, it is required the recalculation of all indicators, to take into account potential positive or negative overlaps in effects assessment.

On this basis it can be concluded that the scenarios combination $\mathrm{B} 1+\mathrm{C} 1$ is positive for all involved stakeholders and can be potentially implemented in addition to the use of electric vehicles with benefits for operator and society and without penalising the customer. 
Table 13: Unit effects (by parcel) of proposed measures and scenarios according to main stakeholder's viewpoints.

\begin{tabular}{|c|c|c|c|}
\hline \multirow[t]{2}{*}{ Measure/Scenario } & \multicolumn{3}{|c|}{ Viewpoint } \\
\hline & Operator & Customer & Society \\
\hline $\begin{array}{l}\text { EV } \\
\text { Electric Vehicles }\end{array}$ & $\begin{array}{c}(-) \\
\text { Costs: }-4 \%\end{array}$ & $\odot$ & $\begin{array}{c}+;)(-) ; \\
\text { Energy: }-67 \% \\
\mathrm{CO}_{2}:-28 \% \\
\text { Other emissions: - } \\
91 \%\end{array}$ \\
\hline $\begin{array}{l}\text { B1 } \\
\text { Back-office/1 }\end{array}$ & $\begin{array}{c}(\odot) \odot \\
\text { Costs: }-25 \%\end{array}$ & $\begin{array}{c}\text { (;) } ; \\
\text { Waiting: }-32 \%\end{array}$ & $\begin{array}{c}\odot \cdot) \\
\text { Energy, } \mathrm{CO}_{2} \text { and other } \\
\text { emissions: }-17 \%\end{array}$ \\
\hline $\begin{array}{l}\text { B2 } \\
\text { Back-office/2 }\end{array}$ & $\begin{array}{c}(-) \\
\text { Costs: }-10 \%\end{array}$ & $\begin{array}{c}(-) \\
\text { Waiting: }-2 \%\end{array}$ & $\odot$ \\
\hline $\begin{array}{l}\mathrm{C} 1 \\
\text { Call center/1 }\end{array}$ & $\begin{array}{c}(-) \\
\text { Costs: }-7 \%\end{array}$ & $\begin{array}{c}(\dot{\ominus})(-) \\
\text { Waiting: }-12 \% \\
\text { Assisted delivery }\end{array}$ & $\begin{array}{c}\odot \cdot) \\
\text { Energy, } \mathrm{CO}_{2} \text { and other } \\
\text { emissions: }-4 \%\end{array}$ \\
\hline $\begin{array}{l}\mathrm{C} 2 \\
\text { Call center/2 }\end{array}$ & $\begin{array}{c}+; \\
\text { Costs: }-2 \%\end{array}$ & $\begin{array}{c}(-) \\
\text { As }\end{array}$ & $\odot$ \\
\hline $\begin{array}{l}\text { D1 } \\
\text { Centers delocalization/1 }\end{array}$ & $\begin{array}{c}\ddot{\partial} \\
\text { Costs: }+2 \%\end{array}$ & $\begin{array}{c}(\cdot) \cdot(-) \\
\text { Waiting: }-25 \%\end{array}$ & $\begin{array}{c}+:)(-) \\
\text { Energy, } \mathrm{CO}_{2} \text { and other } \\
\text { emissions: }-34 \%\end{array}$ \\
\hline $\begin{array}{l}\text { D2 } \\
\text { Centers delocalization/2 }\end{array}$ & $\begin{array}{c}\text { (2) } \\
\text { Costs: }+13 \%\end{array}$ & $\odot$ & $\begin{array}{c}(-) ; \\
\text { Energy, } \mathrm{CO}_{2} \text { and other } \\
\text { emissions: }-26 \%\end{array}$ \\
\hline
\end{tabular}

\section{Final remarks}

The need to assess the measures capable to fulfil environmental and economic aims of operators, customers and Society in the field of urban parcels delivery has been faced by the development and the application of a systematic analysis method based on performances indicators capable to qualify the effect of improving measures, both in technical field (e.g. operation by electric vehicles) and in operational field (e.g. reorganization of service). On the basis of the proposed method it is possible to assess and to select the most effectiveness single and combined measures. The case study of the urban parcels delivery in Rome demonstrated the functionalities of the proposed method and, thanks to the complexity of the case study itself, the possibility to be applied to parcels delivery problem in different urban contexts, as well as to similar problems requiring urban distribution networks (e.g. press, food, security, school), whose peculiarities will be analysed into details in future studies. 


\section{References}

[1] Andrè M. - The ARTEMIS European driving cycles for measuring car pollutant emissions - Science of The Total Environment. 334-335, December 2004.

[2] ANFIA, ACI - Trasporto merci su strada. Analisi economico-statistica delle potenzialità e criticità di un settore strategico per lo sviluppo sostenibile Febbraio 2013.

[3] Dablanc L. - Goods transport in large European cities: Difficult to organize, difficult to modernize - Transportation Research Part A: Policy and Practice, 41, March 2007.

[4] Dablanc L., Rakotonarivo D. - The impacts of logistics sprawl: How does the location of parcel transport terminals affect the energy efficiency of goods' movements in Paris and what can we do about it? - Procedia - Social and Behavioral Sciences, 2, 3, 2010.

[5] Lopez Lambas M.E., Ricci S. - Implementation and management of private traffic limitation in urban areas: experiences and methodologies - Urban Transport XVIII, Transactions of the Wessex Institute, The Built Environment 128, 2012. 